\title{
Technology Leadership in Malaysia's High Performance School
}

\begin{tabular}{l|l|}
\hline Wong Ai Yieng \\
Khadijah Binti Daud ${ }^{2}$ (iD) \\
\hline${ }^{1,2}$ Faculty of Education, Universiti Teknologi Malaysia, Malaysia
\end{tabular}

\begin{abstract}
Headmaster as leader of the school also plays a role as a technology leader. This applies to the high performance schools (HPS) headmaster as well. The HPS excel in all aspects of education. In this study, researcher is interested in examining the role of the headmaster as a technology leader through interviews with three headmasters of high performance schools. Various topics related to technology leadership among headmaster have been discussed based on National Educational Technology Standards for Administrators (NETS-A) 2009 recommended by International Society for Technology in Education (ISTE). From the conversation, the headmaster of HPS have played their leadership role of technology in schools by meeting the various components of NETS-A. In terms of challenges, the online internet is a major obstacle to promoting the use of ICT in the school. The hard work and effort by the headmaster of HPS in the field of ICT has shown a good result and outcome. The headmaster of other schools should have to emulate the great efforts HPS headmasters to create a generation of young literates.
\end{abstract}

Keywords: Technology leadership, Information, Communication technology, High performance school.

\section{Contents}

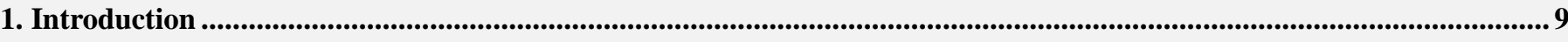

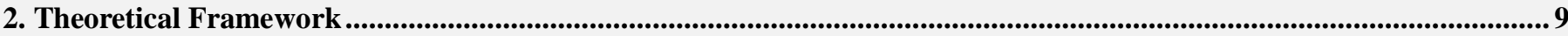

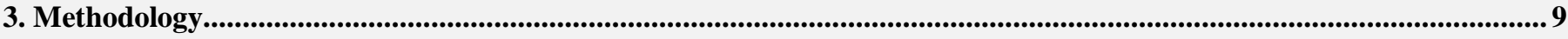

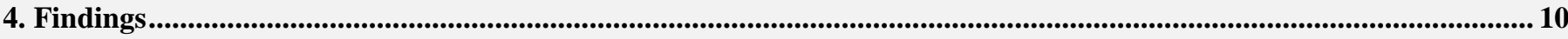

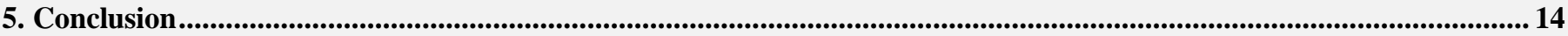

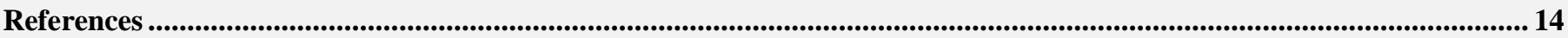

Citation | Wong Ai Yieng; Khadijah Binti Daud (2017). Technology Leadership in Malaysia's High Performance School. Journal of Education and eLearning Research, 4(1): 8-14.

Dear:

$\operatorname{ISSN}(\mathbf{E})$ :

$\operatorname{ISSN}(\mathbf{P})$ :

Licensed:

Contribution/Acknowledgement:

Funding:

Competing Interests:

Transparency:

History:

Ethical:

Publisher: 10.20448/journal.509/2017.4.1/509.1.8.14 Crossref 2410-9991

2518-0169

This work is licensed under a Creative Commons Attribution 3.0 License $(\mathrm{cc}) \mathrm{EY}$

All authors contributed to the conception and design of the study.

This study received no specific financial support.

The authors declare that they have no conflict of interests.

The authors confirm that the manuscript is an honest, accurate, and transparent account of the study was reported; that no vital features of the study have been omitted; and that any discrepancies from the study as planned have been explained. Received: 6 February 2017/ Revised: 22 February 2017/ Accepted: 28 February 2017/ Published: 9 March 2017

This study follows all ethical practices during writing. Asian Online Journal Publishing Group 


\section{Introduction}

Headmaster as the most important and influential person in the school is responsible for all activities that occur in schools (Brockmeier et al., 2005; Grey, 2010; Zuraidah, 2010). As head of the school, he should play a role as a leader of various functions. He is not only as an instructional leader, the leader of the organization, strategic leaders, community leaders, leaders of change but also serves as a technology leader (Flanagan and Jacobsen, 2003; Anderson and Dexter, 2005; Grey, 2010; Leong, 2010; Banoglu, 2011; Mohd, 2011; Richardson and McLeod, 2011; Cakir, 2012; Chang, 2012; Cummings, 2012; Draper, 2013; Fisher and Waller, 2013). This role should be emphasized by the headmaster. As confirmed by Flanagan and Jacobsen (2003) technology literacy represents access to high-tech job market, have the opportunity of participation in the global economy and achieve success in the new information age. Therefore, the task of initiating and implementing change in schools through ICT must be the responsibility of the headmaster (Schiller, 2003).

The same responsibilities goes to the high performance school headmasters. High Performance Schools (HPS) are defined as schools with ethos, character and identity of its own as well as in all aspects of education. These schools also has a tradition of high standard in culture and excellence in human capital in develop holistically and competitive in the international arena (Ministry of Education (MOE), 2010). That is why, SBT often become public choice school. Based on the figures given by the Division of Residential School and the School of Excellence, Ministry of Education in July 2016, HPS posted a total of 132 schools out of a total 10,180 schools in Malaysia. In conclusion, the schools that recognized as HPS is the best school in Malaysia, selected according to the needs and able to compete at the international level. To that end, researchers are interested to know 1) What does technology leadership look like in high performance school? and 2) What are the challenges faced by high performance school headmasters in order to become an effective technology leader?

\section{Theoretical Framework}

To serve as a technology leader, the set standard of the International Society for Technology in Education (ISTE) can be used as a benchmark to the headmaster. National Educational Technology Standards for Administrators (NETS-A) 2009 is a set of standards that gained widespread recognition from around the world and there are many members use in educational institutions of various levels (ISTE, 2009; Morphew, 2012). Under NETS-A, the headmaster is necessary to have 5 criteria: i) visionary leadership, ii) digital age learning culture, iii) excellence in professional practice, iv) systematic improvement, and v) digital citizenship.

Visionary leadership is the first standard to be mastered by the headmaster of the school as a technology leader. In this standard, the headmaster must have a vision of integrating the technology to share with the school teachers to support teaching and learning in the classroom. Therefore, headmaster need to have a continuous strategic technology planning to support the vision of technology that has been created (ISTE, 2009). Next, a variety of policy, program and financial support needed for the implementation of the vision and strategic plan for school technology.

The second standard in technology leadership is digital age learning culture. This standard requires the efforts of headmaster to create a culture of digital learning era. Therefore, headmaster should encourage effective learning through adequate technological equipment. Besides that, headmaster should also serve as a model for promoting the use of technology in learning frequently (ISTE, 2009). It's important to meet the individual needs of the various technologies in the learning process. Headmaster also need to join the learning community-focused innovation at local, national and global.

For the third standard of excellence in professional practice, headmaster should focus on the professional development of teachers. Therefore, sufficient time and resources should be available to enable teachers to improve self-development of technology professionals. Headmaster also need to involve themselves in technology-based professional development. This makes it easier for his/her role as a model for promoting the use of technological equipment in digital era. Headmaster also need to engage with technology-related educational research to help improve student learning.

The fourth standard is systematic improvement. This standard emphasizes the need of headmaster to collaborate with the teachers of the school to collect data, analyze data, interpret the findings and share the findings with a aim to improving teacher performance and student learning. Therefore, headmaster need to recruit and retain technology savvy teachers and staff. Headmaster also need to focus on the technology infrastructure to support the schools' management, operations, teaching and learning" (ISTE, 2009).

Standard digital citizenship is the fifth and final standard for technology leadership. In this standard, a headmaster has a responsibility to ensure that the school community have equal access to digital equipment. In addition, headmaster also need to promote, model and establish policies for the use of digital information technology is safe, ethical and legal. Lastly, digital citizenship facilitate headmaster also includes a school-wide understanding of an involvement in global issues through modern digital communication tools.

\section{Methodology}

This study used a case study approach with interview techniques to collect data about the role of the school headmaster in high-performance school as a leader of technology (Merriam, 1998; Yin, 2003). Interview technique was chosen because it allows headmaster to talk about their experience and their knowledge of technology leadership in schools (Creswell and Plano, 2011). Besides that, the method also allows researcher to face the development of ICT in schools through the use of language and body movements of headmaster. On the basis of maintaining the ethical review, the names of three schools and the names of three headmasters are not mentioned as emphasized by Patton (2007) to hide information of the subjects. The identity of the headmasters are represented with the code 'A' to 'C' in this study. 


\title{
3.1. Data Collection and Analysis
}

The open-ended structured interviews were used to gather the views and feedback from headmasters regarding technology leadership. These interviews form set of questions asked in an orderly arrangement (Mohammad, 2013) and do not deviate out of the original goal of the study and facilitate data analysis.

For data analysis, researcher used the constant comparative method to analyze interview transcripts for theme. Based on the frequency and uniqueness of data, interview transcripts grouped into different categories. Open coding is the initial set codes and follow by axial coding as second stage to make explicit connection between categories. Initial set of codes was refined and expanded based on the data set through this process. Next, the relationship between themes was validating through selective coding. Finally, five standards of NETS-A was used to categorise themes.

Interview questions focused on role of headmaster as technology leader. Various topic related to technology leadership among headmaster have been discussed. The questions aimed to create discussions about all aspects of five standard NETS-A. The following section describes a technology leadership in three different high performance school in Malaysia. Finally, it is followed by challenges of technology leadership in high performance school.

\section{Findings}

\subsection{Technology Leadership in High Performance School First Standard: Visionary Leadership}

All high performance headmaster in this study has technology foresight and vision to support teaching and learning in schools. Therefore, they set the strategic technology planning continuously. Each headmaster shared school technology plans as follows:

\begin{abstract}
"Our schools through the board of management of the school (PTA) involves private companies to schools to improve the use of technology in schools. So, the school with the board of management of the school and with the help of private companies conduct improvements so that we fully utilize ICT equipment. All the old equipment we already exchange to new. Teachers do not plug here and plug there, take a very long time and a waste of time. Improvements made private companies are of better quality and save teachers' time for teaching and learning." (Headmaster A)

"Our school through the PTA have a contract with Edutech private company. So, the company that we assign has the responsibility for all the maintenance. They will take responsibility if there is any kind of damage. So, it does not burden the schools. We contract with a company's every 3 years. If the computer said it was outdated, not suitable for use for filling or use, the company will change, will top up again." (Headmaster B)

"For your information, we're trying to make the paper work to install fiber optics for wifi. We are working in collaboration with the private sector and communities to ensure that fiber optics can be connected here because we can enter unifi. Unifi is more appropriate. We get quotation from outside. We may require to spend nearly RM200, 000. I've appealed minister for donations, during PTA meeting, thru the Ministry of Education ... for it is not for the purposes of my own school. Later on when we can install fiber optic from Saujana chief minister house there, if he continued to SIJS and it will also connect to other secondary school like SIJS, school city high school Ngee heng, even ppd. I'm trying though forced to work hard to get donations. For installation, I contact for help rather than agencies. For example, country development agency. Because it will involve too much cost later. I think RM 20000 was not enough in here. We need to ask for donations from outside. If it can be done... best. I'm champion." (Headmaster C)
\end{abstract}

Apparently, every headmaster of high performance school in this study makes strategic planning to manage the use of technology in schools. Based on the technology vision to be achieved, they make appropriate and necessary improvements with the ultimate goal of maximizing the use of technology among teachers and students for teaching and learning.

\section{Second Standard: Digital Age Learning Culture}

The second standard is the standard most widely discussed by headmaster of the high performance schools. Everyone share lengthy about efforts devoted to complete the technological equipment required by the school. All the headmaster strive to realize the learning culture of the digital age to the school community. Sharings of the headmasters as follows:

\footnotetext{
"This school first need to take a period of time to plug in wiring for different computer equipments. Most teachers are not able to do so. To resolve this problem, the school with the institution administrators with the help from private company makes improvements to the ICT equipment. Now, this school uses smart boards and computers in the classroom and lab computers. All 30 classes from year 1 to year 6 use a smart board and visualizer. It does save time and easy. Now we do not need to wear lenses. Teachers just need to put the book on the visualizer, indeed very easy, clear pictures and very interesting. It also saves teachers' time in conducting teaching and learning. The students not only hear, they can also be see. Next, the students were able to participate and maintain their memory. They understand and apply what they learned." (Headmaster A)
} 
"Before school becomes high performance school, we can only use existing equipment such as software and laptops. But after 2012, after the school received recognition as a high performance school, I use a special allocation provided by MOE and gradually increased smart board in classrooms and up to 2015 , the school has reached $100 \%$ of all classrooms using the smart board. The school has a number of 32 classes but because there is overlap of the morning session and the afternoon session, the number is 50. All classes are equipped with smart board. All curriculum standards follow the provisions of the ministry in the textbooks are installed in the smart board. So, mean teachers do not have to carry textbooks. Teachers can use softcopy. After that, there are also exercises that elicited all higher order thinking skills of students. In addition, we also have two large computer labs in school. Students will enter the computer lab every week. Each week they will use the computer lab for 1 hour. It's compulsory. Each student is exposed to the use of computers and smart program such as 'permata pintar', Frog VLE and Zoom A. We also have a taskforce to sustain and optimize existing equipment and technology to ensure that all existing equipment continues to be used and maintained properly. Close monitoring should be held every time." (Headmaster B)

"To implement the learning of the 21 st century, I try to complete the infrastructure of ICT in the classroom such as installing the class with the smart board. Now there are 14 classrooms and special rooms with smart board facilities. The classes with smart board is 3 classes in years 6 and all classes of years 2 is $100 \%$ with smart board. For special room, 3 labs, interactive science laboratories, JQAF room, music room and pre-school also has a smart board. Interactive laboratory is a laboratory of the provisions of the clusters and in it there are 25 computers. So, we fill with smart board in it. Then, I put 2 smart board in the science lab. Learning science, we want to make it more interesting, see a living thing, so can access using a smart board and internet. Then, we put in a JQAF or Islam room in which I wanted the latest in learning Islamic education. Then, we have smart board in the music room. So, can sing, whistle like a live play. We also put in pre-school. Pre-school must have available the materials of life, clear, visible to the students learn more easily. To date there are a total of 14 smart board.

Maybe next year if there is more money maybe I can add. Because the cost is quite high. For smart board, it cost more than 8 thousand, LCD price in two thousand and PC in two thousand. So, at least there are 12 thousand needed to complete one class. With provision I cannot buy it all. I have other needs like maintenance, internet and computer. On the computer, the number of computers in this school, there are already more than 100 pieces are placed in 3 computer laboratories, a resource centre and access room. The students can use at any time other than the setting in particular ICT timetable. For teachers, all GPK supplied with a computer and a printer. For other teachers, there are computers and printer in counselling room, examination room and SBT room. I already supplied them with computer and printer. I think there is no problem to do the job. That is why many teachers leave school at 4 or 5 pm." (Headmaster C)

The headmaster of the high performance school understands the importance of technology infrastructure role for teachers and students to undergo effective teaching and learning. They perform a variety of effort in equip technological equipment in school. These actions clearly show high performance school headmasters perform the role as a technology leader. School's citizens were given equal access opportunities to use technological equipment in schools. A digital era learning culture exists in the high performance schools.

\section{Third Standard: Excellence in Professional Practice}

The third standard excellence in professional practice focuses on professional development of teachers. All headmasters in high performance schools in this study provide adequate resources and give time off to teachers to enhance the professional development of teachers in technology. Their sharing is as follows:

"Our school is strengthening ICT skills of teachers with programs or courses to teachers. Usually we invite talented people from the private sector or from our own area or ICT teachers which are very talented in this area. We will invite them." (Headmaster A)

\footnotetext{
"We invited experts to teach. It aims to enhance teachers in the use of Frog VLE. Besides that, professional learning community is also used to optimize teaching and learning in the classroom. It is a ways of education in the 21 st century that we are using." (Headmaster B)

"As the school administrator, I ensure that teachers have the skills to use ICT. We conduct inservice training. For in-service training, I use my ICT teacher and several teachers who are skilled in computers. So, there is no reason for school teachers to says they cannot use ICT. They all can use it." (Headmaster C)
}

All the headmasters in this study know the importance of ICT courses for teachers. Therefore, they took the initiative to invite experts to strengthen ICT knowledge and skills of teachers using ICT applications for teaching and 
learning. Both internal and external courses are headmaster's choice depends on the effectiveness of the ICT courses for teachers. All headmasters in high performance schools in the study encourages teachers to carry out teaching and learning using ICT tools in order to achieve the maximum learning objectives.

\title{
Fourth Standard: Systematic Improvement
}

This standard emphasizes the need for headmasters to use data sources to improve teacher performance and student learning. Similarly for headmasters in high performance schools in the study. They use data to achieve the desired learning. Headmasters shared his/her experience as follows:

"PPD Sibu give exposure to all headmasters on the "GROW" program. That means, we will enter all data of students into the program so that we can analyse student progress. Besides that, we have an intervention program so that our students can go forward with the goal there. From time to time, we will monitor and check whether our program is successful or not. If it does not succeed, we must devise another program or other interventions to strengthen. We always make a self-assessment." (Headmaster A)

\begin{abstract}
"The school uses a software system for assessment and evaluation of students' performance. So, the teacher will key in student's achievement and consolidation. After consolidated, the administrator can view at any time. Post-mortems examinations will be made afterwards to assess the performance of students." (Headmaster B)

"We recorded the marks into the SAPS system. On our part there is no problem because apart from the personal computer provided, I also provide a laptop for teachers to fill in marks. There are post mortem held to present the results of students. We take data from the SAPS, we don't print and use less paper. We can present and teachers also have their own computer. They can see themself. Of course we use ICT in schools. Very simple, really." (Headmaster C)
\end{abstract}

The headmaster of high performance school in this study using student test data as a primary source for assessing the achievement of students' learning and to analyze whether the professional development of teachers should be carried out to improve classroom practice. They all use a variety of methods such as the SAPS and GROW to collect data, analyze the data and then interpret student achievement. This system is important for teachers to audit their academic subjects. All these efforts are clearly proved that headmasters in the study make the comprehensive assessment of the effective use of technology.

\section{Fifth Standard: Digital Citizenship}

Digital citizenship is the fifth and final standard. For this dimension, the teacher as the school crest serves as a model for the use of information technology in safely, ethically and legally manner. The headmaster of high performance school in this study meet the requirements contained in this standard. They share experiences as below:

"ICT if we use the right course will give many benefits to the students. It will be bad if we misuse it. They will use ICT to play the game every day and so on. This will affect their learning. So, to avoid misuse of ICT, the school has held talks. We invite people who are experts in this so that they can give warning and of disadvantages if we use ICT wrongly." (Headmaster A)

"For misconduct of ICT, I really pay attention to this issue. Because we have smart board in the classroom, perhaps in the breaks we have students go there for online or web search. So, we must expose this in the school assembly. I advise them on ways of usage and also giving advice to parents to control their children at home about the use of ICT. We also do that in the PTA general meeting. If there is wrongdoing, we must report in Student Discipline Information Systems (SSDM). SSDM is a system for student discipline. We will send to PPD. Currently, we don't have much discipline problem. A bit only. Lazy, not doing homework, come late, it's not a very serious matter. That's it. "(Headmaster B )

"Misconduct use of ICT in school maybe I cannot see exactly but we have the Head of Panel, we have the Chairman of the Social Welfare, so I put these assistants to help. I leave it to them to control misconduct, hacker and so on. I have to remind them. So far, looks like there is no problem. On misconduct among students, perhaps I did not detect any. We add them in Facebook, students also add us. Sometime, we can trace the student always online even after $11 \mathrm{pm}$. If they're still online after $11 \mathrm{pm}$, I'll message on teachers if there are students who are still in facebook $11 \mathrm{pm}$, to call them tomorrow. Do not criticize in that. Nobody can or disposable ... what's that ... message. As soon as we call her to come and see me in the headmaster's office. After that, I will explain. You do not like but can be reached at... If you can not follow the rules, I will remove your name, do not let you in. So, you can just ... so on.. In the assembly, we will remind. We encourage them to add, but for what, we will talked about it. If they wanted to share a picture, I advice them to add photos with good image. For example, if a Muslims, we advice photos with veil in facebook. That's the lesson that we need to emphasize. If you sulk with mom, you do not write in 
facebook. It was personal. So I admonished her. Cannot. That's the secret of your family. The dignity of your family. So we have to take care. Any teacher found, she got the call. If I do not treat her very kind, she said teachers do not talk to me. Yesterday was my birthday. Sometimes we do not open facebook, I do not have time. If free later, I will open facebook. We do not have time, but we add her. We saw. It really happened. "(Headmaster C)

Three headmasters in high performance schools in this study is very aware of the adverse effects of ICT misconduct in school and take proactive measures using a variety of methods to reduce potential violations of ICT in schools. One method is to create awareness among the school community. Giving this awareness is important for students to do the right thing and avoid untoward incidents. The cooperation of parents is also important. So, the school was also given a warning to parents through the PTA general meeting and the notice to parents. It is expected that the cooperation between the school and parents can help students use the full benefits of effective use of ICT for learning.

\title{
4.2. The Challenge Faced By High Performance School Headmasters
}

In the process of moving towards using ICT in various activities at the school, headmasters of high performance schools, like other school headmasters also face many challenges. The majority of headmasters face challenges in the standard 2 digital age learning culture. There are also headmasters also expressed the feelings they have a little hitch in standard 5 digital citizenship. Sharing by headmasters are as follows:

\section{Second Standard: Digital Age Learning Culture}

All three headmasters told that they face constraints in having a strong internet connection for official school business and in teaching and learning. This affect their teaching and learning and provide a barrier to the smooth course of the school.

\begin{abstract}
"In Sarawak here, I think that if compare to the Peninsular Malaysia we are a bit slow in online. We always have trouble on-line, sometimes the system down, sometimes online is not good, and so forth. We got stuck there and a bit too difficult for us if you want data right away. We are facing a very big problem and our teachers always get up early in the morning to grab the line. That's a very big problem and can not be resolved. Perhaps the ministry or the parties they seek to solve this problem in the future so that we do not get stuck there and there are teachers who are afraid of this because the line is not good and they are always worried it was a great pressure on teachers." (Headmaster A)
\end{abstract}

"In terms of the challenges of using ICT that as we use now, all schools are using YES ? Sometimes the line is not strong enough, sometimes there, sometimes none at all, the line problem. For the use of ICT, it was no problem. Only problem getting online. That's all." (Headmaster B)

"So far I have not been successful in terms of a graph of using Frog VLE. So, our schools have not achieved the targets as set by PPD. Not yet achieve usage percentage. Because if we use the computer lab, internet connection is too slow. We also use schoolnet with streamix. Not fast enough. Too slow. So, teachers are not interested because affect teaching and learning." (Headmaster C)

In addition to a poor internet connection, headmaster A also told he faces constraints in the maintenance of ICT equipment in schools. This disrupt a smooth and efficient teaching and learning at school.

\begin{abstract}
"Now the problem is the maintenance of ICT. That's a problem. Maybe next year we will continue to go to this area so that we will be more prepared if we encounter a problem, we ourselves can manage. Not necessarily we always call people outside and we need to wait. That's the problem. The maintenance cost, if we wait for the allocation from ministries will be quite long. Normally we will use "school fund" or we ask for help from the school board to provide maintenance and so on. This is because if we wait, it does affect teaching and learning." (Headmaster A)
\end{abstract}

\section{Fifth Standard: Digital Citizenship}

In addition, headmaster $\mathrm{C}$ also shared her encounter whereas parents do not allow their children to use the internet at home over fears their child internet abuse at home. Headmaster A sharing as follows:

\footnotetext{
"There are some parents who do not allow children to surf the internet because they fear the students will go see things that they should not and so on. But I've been many times tell the parents that they should not leave their own children. If they are concerned, they have to be with her child. That is the latest amenities, cannot stop their child to use it just because they afraid. If he did not allow his son to use, the child will be loss. They cannot find the material." (Headmaster C)
}

Even with high performance school status, school headmasters of high performance school in this study continue to face challenges in the transformation process of the integration of ICT in teaching and learning. Sharing from the headmasters clearly show they face the challenges of the standard 2 digital age learning whereas online culture of the 
Internet is uncertain and the maintenance of ICT equipment. Similarly for the standard 5 digital citizenship also receive complaints from headmasters who say parents do not allow their children to use the internet at home because the worry of Internet abuse for purposes that are not good. Headmasters in this study also address the challenges that occur with multiple follow-up efforts. They tried to solve the obstacles that occur. Strategic technology planning tailor-made for the needs of different schools. Actions and efforts of headmasters prove their worth and capability as a technology leader of the school.

\section{Conclusion}

In tune with the transformation of education planned by the MOE, headmasters of high performance school in this study is not only take a role as leader of the school, instructional leaders, strategic leaders, community leaders, leaders of change but also as a technology leader. They are sensitive to changes in technology and always willing to accept the renewal with an open heart. Indeed, the headmasters in this study devotes effort, energy and time to implement technological innovations required by the school. In other words, the technology leader not only need to meet the various criteria contained in the five standard NETS-A, they also need to act according to changes that apply in school. So, for all the three headmasters of high performance school in this study, they deserve to be held as a technology leader. Although faced with the challenge of technology as other school, headmasters in this study remained persistent in searching for an alternative solution such as MOE motto that is "Move Towards Change, We Cannot Not Change For School." They are headmasters needed by the country. Headmasters of high performance school serves as an examples to the other schools headmasters in role as a technology leader in order to create country's youth who are ICT literated.

\section{References}

Anderson, R.E. and S.L. Dexter, 2005. School technology leadership: An empirical investigation of prevalence and effect. Educational Administration Quarterly, 41(1): 49-82. View at Google Scholar | View at Publisher

Banoglu, K., 2011. School principals' technology leadership competency and technology coordinatorship. Educational Sciences. Theory \& Practice, 11(1): 208-213. View at Google Scholar

Brockmeier, L.L., J.M. Sermon and W.C. Hope, 2005. Principals' relationship with computer technology. National Association of Secondary School Principals Bulletin, 89(643): 45-63. View at Google Scholar | View at Publisher

Cakir, R., 2012. Technology integration and technology leadership in schools as learning organizations. Turkish Online Journal of Educational Technology, 11(4): 273-282. View at Google Scholar

Chang, I.H., 2012. The effect of principals' technological leadership on teachers' technological literacy and teaching effectiveness in Taiwanese Elementary Schools. Educational Technology \& Society, 15(2): 328-340. View at Google Scholar

Creswell, J.W. and C.V.L. Plano, 2011. Designing and conducting mixed methods research. 2nd Edn., Thousand Oaks, CA: Sage.

Cummings, C.D., 2012. A study of technology leadership among elementary principals in a suburban Texas independent school district (Doctoral Dissertation). ProQuest Dissertations and Theses Database. (UMI No. 3510141).

Draper, K.L., 2013. An examination of the relationship between principal technology leadership and technology integration in urban schools. Thesis PHD: University of Oklahoma.

Fisher, D.M. and L.R. Waller, 2013. The 21st century principal: A study of technology leadership and technology integration in Texas K-12 Schools. Global ELearning Journal, 2(4): 1-44. View at Google Scholar

Flanagan, L. and M. Jacobsen, 2003. Technology leadership for the twenty-first century principal. Journal of Educational Administration, 41(2): 124-142. View at Google Scholar | View at Publisher

Grey, B.J.E., 2010. A study of technology leadership among elementary public school principals in Miami-Dade County. Tesis Phd: St. Thomas University.

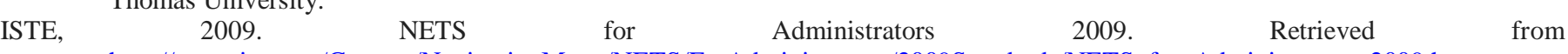
http://www.iste.org/Content/NavigationMenu/NETS/ForAdministrators/2009Standards/NETS_for_Administrators_2009.htm.

Leong, M.W., 2010. Principal's technology leadership and teacher's information and communication technology (ICT) application phase in schools at Seremban. Unpublished Master Project Paper. Kuala Lumpur: Universiti Malaya.

Merriam, S.B., 1998. Qualitative research and case study applications in education. San Francisco, CA: Jossey-Bass.

Ministry of Education (MOE), 2010. Implementation of high performance schools. MOE: Cyberjaya, Selangor.

Mohammad, Z., 2013. Mixed method research: Instruments, validity, reliability and reporting findings. Theory and Practice in Language

Studies, 3(2): 254-262. View at Google Scholar | View at Publisher

Mohd, J.S., 2011. In: Principal's technology leadership at A smart school in Kota Tinggi, Johor. Unpublished Master Project Paper. Kuala Lumpur: Universiti Malaya.

Morphew, V.N., 2012. A constructivist approach to the national educational technology standards for teachers. International Society for Technology in Education: 1-61.

Patton, M.Q., 2007. Qualitative research and evaluation methods. 3rd Edn., Thousand Oaks, CA: Sage.

Richardson, J.W. and S. McLeod, 2011. Technology leadership in native American Schools. Journal of Research in Rural Education, 7(26): 114. View at Google Scholar

Schiller, J., 2003. The elementary school principal as a change facilitator in ICT integration. Retrieved from http://technologysource.org/article/elementary_school_principal_as_a_change_facilitator_in_ict_integration.pdf.

Yin, R.K., 2003. Case study research: Design and methods. 3rd Ed., Thousand Oaks, CA: Sage, 5.

Zuraidah, A., 2010. Learning organizations in the management of human capital among the school staff. In Shahril @ Charil Marzuki, Rahimah Ahmad, Hussein Ahmad. Principal Leadership Generate Human Capital In Effective Schools. Selangor: PTS Profesional Sdn Bhd. 